\title{
The Manifestation of Individual Psychological Characteristics of Students in a Situation of Knowledge Testing: Features of Work
}

\author{
Irina Morozikova ${ }^{1, a}$, Kseniya Kuzmina ${ }^{1, b}$, Natalya Kuznetsova ${ }^{2, c *}$ \\ 1 Smolensk State University, 214000, 4 Przhevalsky str., Smolensk, Russia \\ 2 Moscow State University named after M. V. Lomonosov, 119899,1 Leninskiye Gory, Moscow, \\ Russia

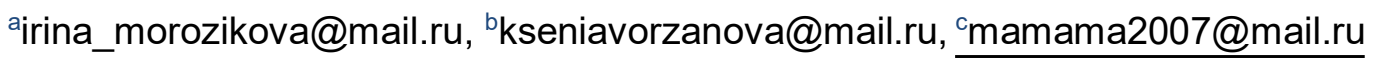 \\ ${ }^{*}$ Corresponding author
}

Keywords: individual psychological characteristics of a student, character accentuation, selfassessment, level of aspirations, anxiety, knowledge testing situation

\begin{abstract}
The article substantiates the need to take into account individual psychological characteristics of schoolchildren, in particular, character accentuations, self-assessment of personality, level of aspirations and anxiety in preparation for the examination of knowledge; generalized experience with different categories of children. The results of diagnostics to identify accentuations of character, anxiety, level of self-esteem, and schoolchildren's claims are given (on the example of grades 9-11 of Smolensk). It is noted that the majority of schoolchildren have subjective difficulties in a situation of testing knowledge. The authors give a psychological assessment of individual psychological characteristics in terms of their influence on the results, highlight advantages and disadvantages. Also, the paper describes features of working with different categories of students. Emphasis is placed on the organization of psychological work not only with students, parents, and teachers.
\end{abstract}

\section{Introduction}

Individual psychological characteristics of a student very often influence not only the process and result of mastering educational materials, but also results of knowledge testing. In some children, the anxiety caused by a stressful situation of the test may become so high that it causes a disruption of activity, which is manifested in the fact that a student cannot perform the simplest tasks, makes clerks, and elementary mistakes. There is a discrepancy between results of testing knowledge and abilities of children, which leads to the formation of inadequate perceptions about capabilities of a student from both the teachers and students themselves. This, in turn, complicates the learning process and creates negative moments.

\section{Methodology}

The study uses a set of techniques that aims to identify among students (grades 9-11) individual psychological characteristics that affect results of knowledge testing. The psychodiagnostic complex was tested in schools in the city of Smolensk (123 pupils, 9-11 classes).

The psychodiagnostic study included the following steps: preparatory, diagnostic, data processing and interpretation, and development of recommendations.

At the preparatory stage, work was carried out with scholarly sources and the selection of psychodiagnostic tools. At the same time, a psychodiagnostic complex was developed to identify individual psychological characteristics affecting the results of the knowledge test, stimulus material and forms for students' answers were prepared.

At the diagnostic stage, we conducted psychodiagnostics of the level of personal and reactive anxiety of students, the level of self-esteem, the level of achievement motivation, and other indicators.

At the next stage, quantitative and qualitative processing of test results data was carried out for each student. Tables of psychodiagnostic indicators were compiled, their psychological assessment was carried out, and individual psychological characteristics were identified that affect individual results. The average 
group indices are calculated, general patterns and trends are determined using mathematical data processing methods.

At the last stage, recommendations were developed on preparing for the situation of testing students' knowledge, taking into account individual psychological characteristics, instructions were prepared for working with students who have problems in the motivational sphere and self-assessment, with anxious children, and with students who have pronounced accentuations of character.

\section{Research}

Psychological problems in the education system are extensively studied by a number of Russian psychologists I(. V. Dubrovina, A. V. Morozov, A. M. Prikhozhan, A. G. Shmelev, and others) as well as by foreign ones (R. Iucu, R. Jones, D. Houlihan, C. Leaper Chapter, M. Platis, etc.) [1; 5; 6; 9; 12-15].

The study of the peculiarities of psychological support and the preparation of graduates for the final certification was carried out by N. P. Badina, K. E. Kuzmina, I. V. Morozikova, M.Y. Chibisova, and others $[2 ; 3 ; 4 ; 11]$.

Russian teachers of psychology, namely G. N. Budnevich, E. V. Guskova, N. Koroleva, N. N. Savchenkova, N. Stebeneva, and others, have accumulated considerable practical experience in preparing eleventh grade students for final exams in various regions of Russia [10].

Research on the problem and the analysis of practical experience show that individual psychological characteristics such as anxiety level, self-esteem, achievement motivation (failure avoidance) and character accentuation have a strong influence on the student's reactions in a knowledge-testing situation. Often, problems arise because schoolchildren are lost in an unfamiliar environment, cannot determine the essence of the task, feel anxiety and anxiety, which prevent them from efficiently organizing the activity $[3 ; 10]$.

There are the following contradictions in the organization of testing students' knowledge:

- between the desire for a differentiated approach to learning and the lack of psychological support adequate in its content;

- between the relevance of leveling an impact of individual psychological characteristics on results of knowledge testing and lack of a scientifically-based theoretical and applied targeted concept of such support in school.

Every year there is a tightening of requirements for examinations, which negatively affects the emotional state of children, their performance, and their results. Sometimes, a student cannot perform the most simple tasks and makes elementary mistakes.

Many schoolchildren have subjective difficulties in testing knowledge, which are determined by their individual psychological characteristics and do not depend on children's readiness in the subject. A summary of the experience of conducting examinations in Russian schools shows $[3 ; 4 ; 11]$ that individual psychological characteristics, such as anxiety level, self-esteem, achievement motivation (failure avoidance), and character accentuation, have a strong influence on students' reactions in the control situation and certain results.

In our study, a set of methods is used, which is aimed at identifying individual psychological characteristics in students (in grades 9-11), which affect results of knowledge testing. Relying on this, one can diagnose such individual psychological characteristics of students as:

- the level of the examination and personal anxiety of students;

- features of self-esteem of schoolchildren;

- features of the motivational sphere of children's personality;

- accentuation of character;

- level of mental development.

The complex includes the following techniques $[7 ; 8]$ : 
- Questionnaire of exam anxiety (A. O. Prokhorov);

- The scale of personal and situational anxiety (Ch. D. Spielberger, modified by Y. L. Hanin);

- Methods for studying the self-assessment (Dembo-Rubinstein, modified by A. M. Prikhozhan);

- Test questionnaire to measure the achievement motivation (A. Mehrabian, modified by M. Sh. Magomed-Eminov);

- Questionnaire of accentuations of character (H. Shmishek).

The proposed psychodiagnostic complex was tested in schools in the city of Smolensk (123 pupils, 911 classes / grades).

Below is an analysis of the diagnostic results.

Analysis the results obtained, one can conclude that $63.6 \%$ of children have character accentuations (see Fig.1). The most common are: exaltation (45.5\%) and hyperthyme (36.4\%). In addition, there are children with such features of character as demonstrativeness, emotionality, cyclotemesty, and sticking.

\section{Accentuation Characteristic}

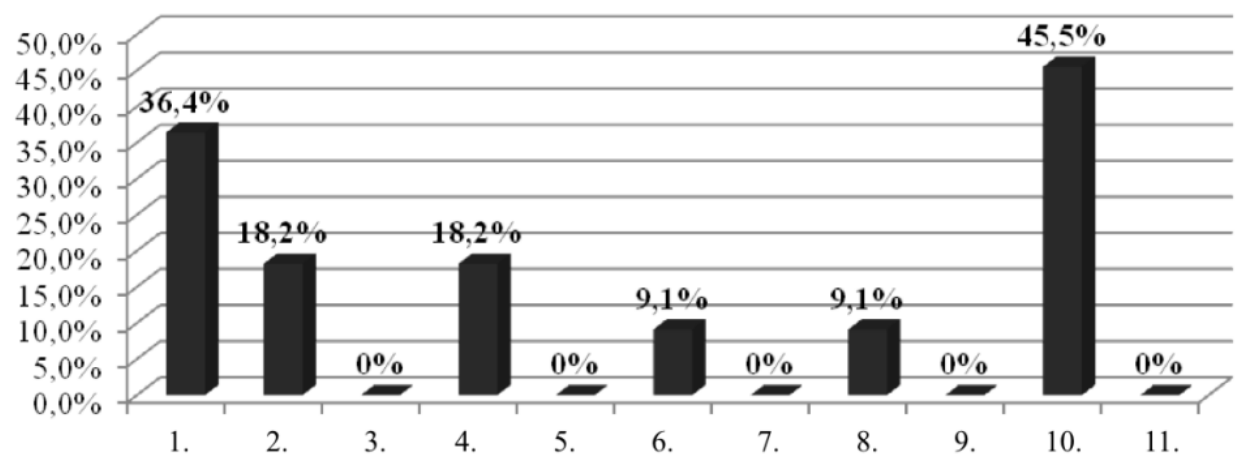

1 - Hypersensitivity. 2 - Emotionality. 3 -Anxiety. 4 - Demonstrativeness. 5 - Distimichniy. 6 - Jamming. 7 - Pedantry. 8 - Cyclothyme. 9 - Excitability. 10 - Exaltation. 11 - Lying.

Fig. 1. Representation of character accentuations in a sample of schoolchildren.

After conducting a psychodiagnostic examination, quantitative and qualitative processing of test results data was carried out for each student. Summary tables of psychodiagnostic indicators were compiled for all schoolchildren, their psychological evaluation was carried out, and character accentuations were identified that determine individual results. It is noted that the students with accentuations experience subjective difficulties in a situation of testing knowledge.

So, hyperthymic students are very active, which in a situation of knowledge testing is manifested in the inability to focus for a long time, the inability to properly end their started business (jumping from one task to another), and the frivolous attitude to activity.

Exalted schoolchildren emotionally react to a stressful situation, they may behave outside the box.

Cyclothymic students are characterized by a periodic change of the phases of activity and passivity. Not being able to control your behavior can lead to a delay in time when solving tasks.

Children with a stuck accentuation need time to enter activities. They are difficult to switch from one type of activity to another.

Emotional children (being in a stressful situation) are sensitive to changes and very vulnerable.

The results of study showe that in the sample, more than half of the children have character accentuations. To overcome students' subjective difficulties in a testing situation, it is necessary to organize psychological work with them and involve parents, class teachers, and subject teachers.

When working with high school students in a situation of knowledge testing, the most pronounced 
accentuations of character were noted, namely: hyperthymic, cycloid, stuck, excitable and demonstrative. In each of them, one can highlight advantages and disadvantages of character.

\section{Hyperthymic type}

Those advantages that affect results of knowledge testing: energy, thirst for activity, optimism, sociability. Character disadvantages: superficiality, inability of prolonged concentration, inability to end an activity, frivolous attitude to activities, a tendency to break the rules.

\section{Cycloid type}

Advantages of nature that affect the results of knowledge testing: initiative, cheerfulness (in the hyperthymic phase); good faith, seriousness (in the hypothetical phase). Character disadvantages affecting results of knowledge testing: frequent periodic mood swings, inconsistency, outbreaks of irritation, sensitivity and pickiness, indifference (in the hypothetical phase).

\section{Stuck type}

Character advantages: the desire to achieve high performance in any business, high demands on oneself, sensitivity to manifestations of social justice, diligence, developed sense of duty. Character disadvantages: sensitivity and emotional unbalance associated with it, arrogance, high demands on others.

\section{Excitable type}

Advantages: conscientiousness, accuracy, persistence, punctuality (in an emotionally calm state). Character disadvantages: slowness of verbal and non-verbal reaction (in an emotionally calm state); excessive aggressiveness, hot temper, poor control of behavior, inability to take into account opinions of the others (in a state of emotional arousal).

\section{Demonstrative type}

Character advantages: initiative, activity, resourcefulness, pronounced organizational skills, originality of thinking. Character disadvantages: boasting of nonexistent successes, high level of aspirations, but "shirking" from work, overestimated self-esteem, and "thirst" for praise, self-centeredness, a tendency to intrigue.

A well-known fact of age psychology is that a high level of anxiety is characteristic of adolescents and young people. This is due to the intensive formation of self-awareness and self-esteem, the instability of ideas about yourself, uncertainty, social shyness. Students at this age, especially adolescents, poorly reflect on their experiences and are even worse able to cope with them. Therefore, they often disguise their anxiety and uncertainty with frankly insolent behavior or demonstrated indifference to the results of their activities, in particular the results of knowledge testing.

Psychological work with students on the formation of the "optimal" (Ch. D. Spielberger, Y. L. Khanin) level of anxiety is necessary [8]. The intimidation of children, which is usual for teachers and parents (as a test of knowledge, exams, tests) leads to disruptive anxiety or indifference (a very low level of anxiety). In the first case, a child experiences such a strong fear that he cannot work in full force of his abilities and knowledge. In the second case, he refuses to study and performs only a minimum number of tasks during the examination of knowledge.

A high level of examination anxiety was found in $18.2 \%$ of students in the sample. They show anxiety in a situation where knowledge is tested, and they are very emotional. This prevents them from concentrating on tasks and successfully completing them. Additional training of students is needed for methods of emotional self-regulation and transfer of attention from the situation of knowledge testing to the process. It is desirable to reduce the significance of such situation to the optimal level.

For young men and especially teenagers, the age feature is the inadequacy of self-esteem, and even more so the level of claims. Children with low self-esteem, as a rule, do not atempt to solve difficult tasks, they doubt the correctness of their reasoning, they check themselves several times, losing time. Teenagers and young men with high self-esteem believe that they do not need to prepare for testing, during the testing they take up difficult tasks, neglecting simple ones. 
The method of Dembo-Rubinstein in the modification of A. M. Prikhozhan [1;9] reveales features of self-esteem and level of students' claims. Almost all students in the sample (90.9\%) have an overestimated level of claims. Respondents with a high level of aspirations claim high achievements, including in educational activities. In some cases, this is an incentive for development, learning, self-education, in others it manifests itself as unreasonable expectations of high assessments of the results of its activities and complaints to others about the prejudice.

Only $45.5 \%$ of schoolchildren have an adequate self-esteem. In the sample of respondents, high selfesteem prevails. Thus, student self-assessment processes tend to overestimate. In combination with an overestimated level of claims, they can be an obstacle in personal development, create difficulties in learning by type: "I already know everything, you underestimate me". In a situation of testing knowledge, they tend to choose difficult tasks, not always relying on their strength.

A moderate discrepancy between the level of claims and the level of self-esteem was found in $36.4 \%$ of students, in the remaining $63.6 \%$ - inadequate discrepancy, including low degree of discrepancy (18.2\%) and high degree of discrepancy $(54.6 \%)$. Students with a moderate discrepancy between the level of aspirations and the level of self-esteem set goals that they can actually achieve. In the case of a low discrepancy between the levels, the claims do not serve as an incentive for personal development, the formation of one or another side of the personality. The high degree of discrepancy indicates a conflict between what each student seeks and what he or she considers possible.

\section{Conclusion}

Individual psychological characteristics of students affect results of knowledge testing and are the basis for organizing psychological support. Knowledge of these features allows one to identify psychological reasons for the discrepancy between results and children's actual knowledge, to understand their strengths and weaknesses. It also makes possible to build work on the psychological preparation of students, taking into account their individual characteristics. It is necessary to work to identify subjective difficulties and individual psychological characteristics of students that affect results of knowledge tests, and to prepare students for testing based on the data obtained. It is important to carry out not only work with children, but also with parents, teachers, to organize psychological and pedagogical support.

\section{References}

[1] Andreeva, A. D., Danilova, E. E., \& Prikhozhan, A. M. (2012). Actual problems of practical psychology of education abroad. Modern foreign psychology, 1. 2, pp. 29-38. Retrieved from http://psyjournals.ru/jmfp/2012/n2/52259.shtml.

[2] Badina, N. P. (2005). Psychological preparation of graduates for the Unified State Exam. Pedagogical Trans-Urals, 1, pp.33-35.

[3] Morozikova, I. V., \& Kuzmina, K. E. (2013). Influence of individual psychological characteristics of students on test results as a problem of psychological support of test technologies. Psychology of human health in a globalizing world. Collection of articles of the International Scientific Conference (pp. 310-314). Astana, Kazakhstan: Eurasian National University named after L. N. Gumilyov.

[4] Morozikova, I. V., \& Kuzmina, K. E. (2015). Influence of individual psychological characteristics of students influencing the results of final testing. In Druzhininsky readings: Proceedings of the XIV AllRussian Scientific Practical Conference (p. 38-44). Sochi, Russia: SSU.

[5] Morozov, A. V. (2015). Understanding the nature of mental processes in the domestic psychological science. Scientific Search, 3(3), pp. 67-70.

[6] Morozov, A. V. (2016). Psychological support of subjects of educational relations in the modern communicative space. In Education and personal development in the modern communicative space: Proceedings of the All-Russian Scientific and Practical Conference with international participation (pp. 308-315). Irkutsk, Russia. 
[7] Krylov, A. A., \& Manichev, S. A. (Eds.) (2010). Workshop on general experimental and practical psychology. SPb, Russia: Peter.

[8] Prokhorov, A. O. (Ed.) (2004). Workshop on the psychology of states. SPb. Russia: Rech.

[9] Dubrovina, I. V. (Ed.) (2004). Practical psychology of education. SPb. Russia: Peter.

[10] Savchenkova, N. N. (2013). Teacher's test culture: regional experience of formation. Retrieved from htpp: www.science-education.ru/113-11553.

[11] Chibisova, M. Y. (2008). Psychological preparation for exams: working with students, teachers, parents. Moscow, Russia: Genesis.

[12] Shmelev, A. G. (2013). Practice Testing: Testing in Education, Applied Psychology and Personnel Management. Moscow, Russia: Infra-M.

[13] Iucu, R., \& Platis, M. (2010). Personal and organizational development in education in the context of economic and technological changes. Retrieved from http://www.sciencedirect.com/science?_ob $=$ ArticleURL\&_udi=B9853-5016P5K-B1.

[14] Houlihan, D., \& Jones, R. (1989). Treatment of a boy's school phobia with in vivo systematic desensitization. Professional School Psychology, 4, 4, pp. 285-293. Retrieved from $\mathrm{http} / / /$ search.ebscohost.com/login.aspx?direct=true \&db=pdh\&AN=spq-4-4-285\&lang=ru\&site=ehostlive.

[15] Leaper Chapter, C. (2011). More Similarities than Differences in contemporary Theories of social development? In A plea for theory bridging. Advances in Child Development and Behavior, 40, pp. 337-378. Retrieved from http://www.sciencedirect.com/science/article/pii/B9780123864925000099. 